\title{
The PREE after minimal acquisition: Goal box placement with single pellet reward ${ }^{1}$
}

\author{
GARVIN McCAIN, University of Texas at \\ Arlington, Arlington, Tex. 76010
}

Two groups of rats were given goalbox placements directly over the food cup. Group $P$ was rewarded with a single 1,000-mg pellet on Placements 1, 3, and 5, while Group $C$ was rewarded on each placement. The usual PREE was obtained when Ss ran the full length of the alley. The study supports earlier results and extends them to a single pellet reward situation.

A number of studies (Theios \& Polson, 1962; Trapold \& Doren, 1966; Trapold \& Holden, 1966; Fitzgerald \& Teyler, 1968; McCain, Baerwaldt, \& Brown, 1969) have used goalbox (GB) placement without running trials in an alley and followed this training with extinction, using both alley and GB. Fitzgerald and Teyler found an extinction effect only when the GB placements were reinforced on $50 \%$ of the trials. Except as noted below, the other studies cited found no significant extinction effects that could be attributed to $\mathrm{GB}$ placement.

The McCain et al studies did obtain significant extinction effects from GB placement without running. Three studies were reported; one used nonreinforced placement trials followed by reinforced running trials, a second used nonreinforced trials followed by reinforced placements, and the third had only placements reinforced on $50 \%$ of the trials. In each case, a comparison group was given consistently reinforced running and/or placement trials. The usual PREE was obtained in each study. A small number of acquisition trials was used since this was expected to minimize the probability of discrimination between placement and running trials. In other studies, Wilton (1967) and Capaldi (1968) have obtained differential extinction effects using a substantial number of placement trials. In view of their results, the role of discrimination is not clear. Both Wilton and Capaldi used techniques that differ from those in the present study as well as from the placement studies cited earlier. The basis for differences in results from placement studies is of interest but has not been resolved.

The present study had two purposes. The first was to reexamine the McCain et al result which indicated that GB placements without running could produce a PREE. A second and incidental purpose is related to the Amsel et ai (1969) proposal of a multiple-response explanation for the achievement of a PREE using a minimal number of acquisition trials. Amsel's explanation required that the animal make responses to each of several pellets. In two earlier studies (McCain, 1968, 1969), a PREE was achieved using single pellets and runway trials. The present study also used single pellets and represents an extension of the two earlier studies.

\section{SUBJECTS AND APPARATUS}

The Ss were 42 naive rats of the Wistar strain from the University of Texas at Arlington colony. Ss were approximately 90 days old at the beginning of the experiment and approximately equal numbers of each sex were used. Two straight alleys were used, one for the exploration phase, the other for the GB placement and extinction phase. Each alley had three photoelectric cells and four clocks, with start- and goalboxes separated from the run section by guillotine doors. The test alley was approximately $6 \mathrm{ft}$ long and was divided into three sections, Run 1 $\left(R_{1}\right)$, Run $2\left(R_{2}\right)$, and goal $(G)$, for timing purposes. A full-alley measure was also taken. A more complete description of the test alley may be found in McCain (1968).

\section{PROCEDURE}

On Day 1, Ss were placed on food deprivation and were not fed for $48 \mathrm{~h}$. A 23-h deprivation schedule was then begun. On Days 2-8, Ss were handled, and Purina lab chow was available on the handling table on Days 3-8. On Days 9-12, all Ss were placed in the exploration alley for 15 -min periods daily in groups of three Ss. No food was available in the alley, but Ss were given access to lab chow for $1 \mathrm{~h}$ daily, beginning approximately $15 \mathrm{~min}$ after exploration. On Days 12 and 13, each $S$ was given several 1,000-mg Noyes pellets in his home cage just prior to regular feeding so that Ss would become accustomed to eating these pellets. On Day 12, Ss were assigned to individual cages on a random basis, and on Day 13, Ss were put on a feeding schedule such that they were fed approximately $24 \mathrm{~h}$ before being run on Day 14. Two groups were formed, and Ss in the groups were run in an ABBA order. All Ss were given five GB placements and 10 extinction trials in the test alley. On GB placements, each $S$ was placed so that his head was immediately over the goalcup. Group P was reinforced with a single 1,000-mg Noyes pellet on Placements 1,3, and 5; Group $\mathrm{C}$ was reinforced on all five placements. On nonreinforced trials, Ss from Group $P$ were placed in the GB and detained for $20 \mathrm{sec}$. In extinction, Ss were placed in the startbox, and the guillotine door was raised when the $S$ was facing it. During extinction, Ss that did not reach the GB within $40 \mathrm{sec}$ were guided and confined for the regular period. There was a maximum score of $10 \mathrm{sec}$ for any section of the alley and $40 \mathrm{sec}$ for the full alley. Ss were confined to the GB for approximately $20 \mathrm{sec}$ on each extinction trial, with a 15-sec ITI spent in the waiting cage. As has been typical in studies using small trials, rather strict criteria for dropping animals were stipulated. If $E$ made a single procedural error, the $S$ was dropped immediately. Ss were also dropped if they failed to reach the GB within $40 \mathrm{sec}$ on each of the first three extinction trials. Five Ss were dropped, three due to experimental error and two for failing to reach the GB.

\section{RESULTS AND DISCUSSION}

In Fig. 1 ( $a, b, c$, and d), the first extinction trial and means from blocks of three extinction trials are plotted for the $R_{1}, R_{2}, G$, and full-alley measures. Scores of all Ss were used in the plotted data rather than the centered scores mentioned below.

On each measure, Group $P$ runs faster than Group C during extinction. If all scores are used, the results are in the same direction, and with $\mathrm{df}=1 / 35$ in each case: $\mathrm{R}_{1}$ times, $\mathrm{F}=2.95, \mathrm{p}<.10 ; \mathrm{R}_{\mathbf{2}}$ times, $F=8.57, \quad p<.01 ; G$ times, $F=4.40$, $\mathrm{p}<.05$; total times, $\mathrm{F}=3.85, \mathrm{p}<.07$. Earlier (McCain, 1968), it was proposed that in studies using a small number of acquisition trials the centered $60 \%$ of Ss' scores should be used for analysis. On that basis, the same order of differences is obtained as when all scores are used. With $\mathrm{df}=1 / 23$ in each case, $R_{1}$ times, $\mathrm{F}=6.91$, $\mathrm{p}<.02 ; \mathrm{R}_{2}$ times, $\mathrm{F}=28.64, \mathrm{p}<.001 ;$ $G=2.94, p<.10 ;$ total times, $F=7.86$, $\mathrm{p}<.015$.

These results are in agreement with those reported in McCain et al (Experiment 3, 1969) in that differential effects were obtained when training was confined to placement directly in the GB with no detectable running. There is no particular reason to change the explanation offered in that paper.

It is still not clear exactly why the present results and those from the three earlier studies (McCain et al, 1969) differ from those of Theios, Trapold, and Fitzgerald. The most obvious difference is the number of training trials. In any event, the studies from this laboratory together with studies by Wilton (1967), Capaldi (1968), and, in a slightly different context, Senkowski et al (1968) clearly indicate 

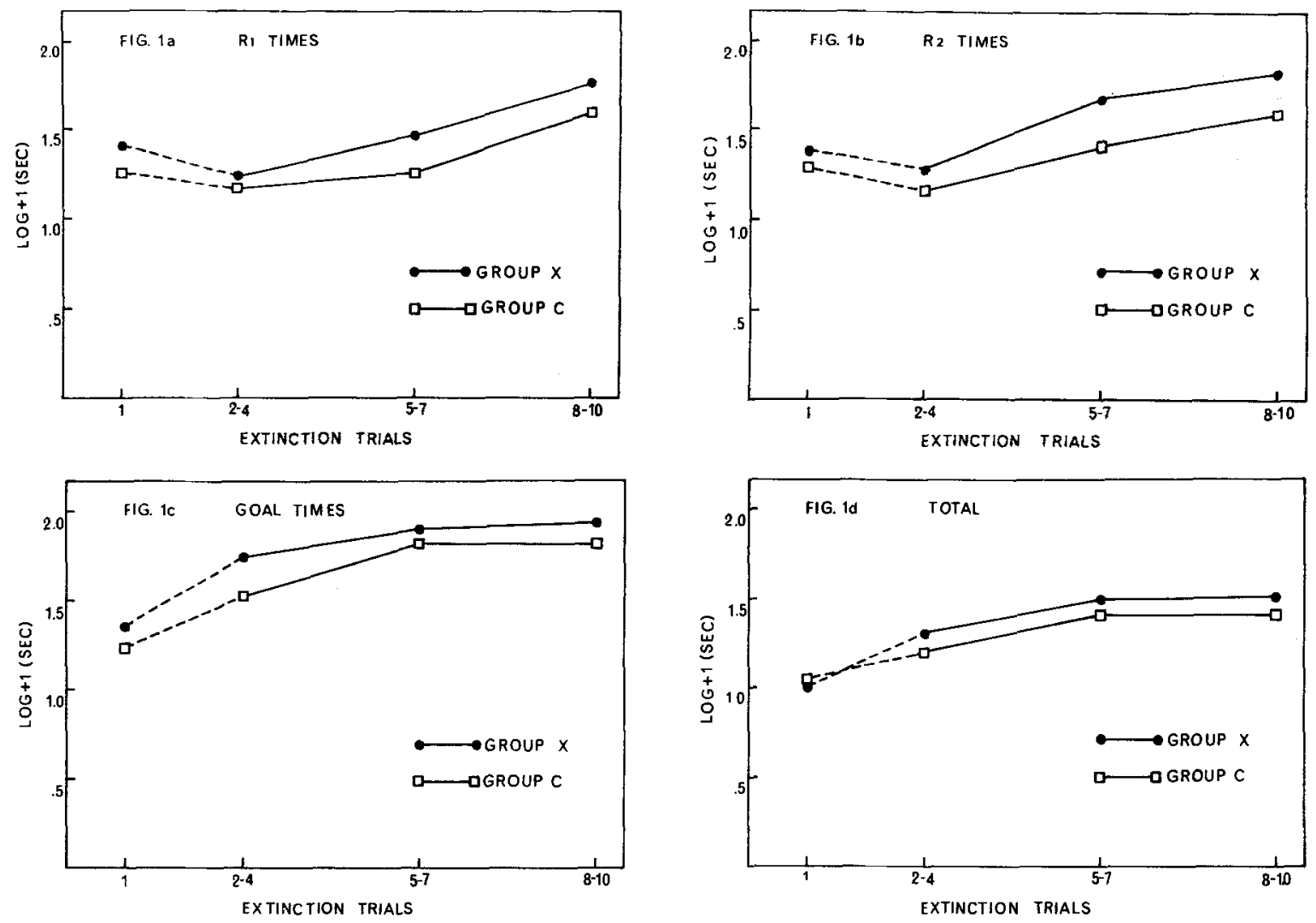

Fig. 1. (a, b, c, and d) Running times during extinction over four sections of

the alley.

that direct GB placement with no apparent locomotion does influence subsequent locomotion.

The production of a PREE using single-pellet reward and a small number of acquisition trials (McCain, 1968, 1969) was also supported. The significance of achieving a PREE with a single-pellet reward and a small number of trials has also been examined before (Amsel et al, 1968; McCain, 1968, 1969).

Finally, the results indicate that exploration of the test alley is not critical to achievement of a PREE when a small number of placements is used.

\section{REFERENCES}

AMSEL, A., HUG, J. J., \& SURRIDGE, C. T. Number of food pellets, goal approaches, and the partial reinforcement effect after minimal acquisition. Journal of Experimental Psychology, 1968, 77, 530-534.
CAPALDI, E. J. Effect of performing a portion of the instrumental reaction on the entire instrumental reaction. Address to Interuniversity Psychology Colloquium, February 1968.

FITZGERALD, R. D., \& TEYLER, T. J. Extinction of a runway response following non-contingent partial reinforcement and nonreinforcement in the goal box. Journal of Comparative \& Physiological Psychology, $1968,65,542-544$.

McCAIN, G. The partial reinforcement effect after minimal acquisition: Single pellet reward. Psychonomic Science, 1968, 13, 151-152.

McCAIN, G. The partial reinforcement effect after minimal acquisition: Single pellet reward, spaced trials. Psychonomic Science, 1969, 15, 146.

McCAIN, G., BAERWALDT, J., \& BROWN, E. R. Extinction following a small number of goal box placements. Canadian Journal of Psychology, 1969, 23, 274-284.

SENKOWSKI, P. C., PORTER, J. J., \& MADISON, H. L. Goal gradient effect of incentive motivation $(\mathrm{K})$ manipulated through prior goal box placements. Psychonomic Science, 1968, 11, 29-30.

THEIOS, J., \& POLSON, P. Instrumental and goal responses in nonresponse partial reinforcement. Journal of Comparative \& Physiological Psychology, 1962, 55, 987-991.

TRAPOLD, M. A., \& DOREN, D. G. Effect of noncontingent partial reinforcement on the resistance to extinction of a runway response. Journal of Experimental Psychology, 1966 , 71, 429-431.

TRAPOLD, M. A., \& HOLDEN, D. Noncontingent partial reinforcement of running: A replication. Psychonomic Science, 1966, 5, 449-450.

WILTON, R. Extinction of a runway response following runway or goal box partial reinforcement. Quarterly Journal of Psychology, 1967, 19, 162-165.

NOTE

1. This study was supported by NIMH Grant 14686-01. Thanks are due to Robert Rose who ran the Ss. 